\title{
A Bibliophile \& Merchant in Shanghai During Modern Times: Zhang Zhiming
}

\author{
Zhu Jieli, Wang Xirong* \\ Department of Editing and Publishing, University of Shanghai for Science and Technology, Shanghai, China \\ Email address: \\ wxr272@163.com (Wang Xirong) \\ ${ }^{*}$ Corresponding author
}

\section{To cite this article:}

Zhu Jieli, Wang Xirong. A Bibliophile \& Merchant in Shanghai During Modern Times: Zhang Zhiming. Humanities and Social Sciences. Vol. 6, No. 5, 2018, pp. 137-142. doi: 10.11648/j.hss.20180605.11

Received: August 27, 2018; Accepted: September 26, 2018; Published: October 26, 2018

\begin{abstract}
Zhang Zhiming was a famous merchant as Ningbo Gang and bibliophile in Shanghai during modern times. He liked ancient books and collected them, established successively private library named "Gu Huan Room" in Tokyo and Shanghai. This paper introduces Zhang's life story and circle of friends, analyses the thoughts, characteristic, usage and dissemination of his collecting books. Collections involve ancient and modern ones within or outside China, among which there are some science and technology books that are not collected by ordinary book collectors. This may be related to his experience in sinification of science. His action of searching and collecting books and other related activities are based not only on a batch of Chinese cultural relics flowing to other countries such as Japan during the Late Qing Dynasty and Early Republic of China, but also because of the Chinese traditional culture and his hometown's culture of collecting books. It is also related to his nature of loving books and the knowledge he has learned in Japan and Shanghai. His practice of collecting books has contributed to the inheritance and protection of Chinese culture to a certain degree, and leaving an indelible impression in the history of modern Chinese culture.
\end{abstract}

Keywords: Zhang Zhiming, Gu Huan Room, Bibliophile, Collection Practice, Sinification of Science

\section{Introduction}

Zhang Zhiming (1872-1947), early steeped in the industrial activities of the sinification of science, has selected and collected the treasures of ancient books, with the help of which he could utilize what he cherished to engage in drawing and compilation of maps and the composition of the chronicles and genealogies and thus he has been comparatively praised as Fu Sheng, the highly honored founder of literature in Han by the versatile learner Ye Gongchuo [1]. And this thesis is aimed to form a clear and vivid picture of this bibliophile, wiping out the false rumor about him while probing into Zhang's life, social activities and the process of his collecting books.

\section{The Brief Sketch of Zhang's Life}

When he was young, Zhang Zhiming entered the private school to study history, geography, and mathematics. When he was 16 years old, after the death of his father, he dropped out of school and went to his ancestral property which called "Xieli" in Chai qiao, zhenhai county(now belong to Beilun district of Ningbo) to learn commerce. After the Xieli was closed, he entered the Fengda Cloth Store in Chaiqiao in the autumn of 1893, and later became an accountant in Xiangxing Fish Store in Chuanshan (this is a street in Chaiqiao, Beilun District). In 1899, Yu Heqin and Zhong Guanguang established a practical learning club in order to study natural science in Chai Qiao.(later known as "Lujiang Club" and "Four bright Club"). Zhang Zhiming went to participate in the activities of this club in his spare time and became a club member. Afterwards, he gave up his own business and devoted himself to the scientific and technological Chinese-industry activities with people like Yu Heqin. In March 1901 (the first month of the 27th year of Guangxu), invited by $\mathrm{Yu}$ Heqin and Zhong Guanguang, he went to Shanghai to join the company of Linguang. Less than half a year, Linguang company closed. In the autumn of 1901, he went to Japan for investigation. At the end of this year, Yu Heqin and others established the first scientific instrument museum opened by the Chinese in Shanghai, and Zhang 
Zhiming was sent to Japan to purchase instruments, specimens, models, etc again for scientific instruments in Tokyo. In the meanwhile, Zhang Zhiming also worked as a clerk at the store "Lingyunge", which sold Chinese books and stationeries and was run by Ningbo Cixi merchant Wang Yizhai, this experience gave him a chance to get in touch with a large number of ancient Chinese books which had been lost to Japan. At the beginning of the 20th century, he collected some plant specimens from the Ningbo area and sent it to Japanese botanist Tadahisa Matsuda for identification. Eventually, it promoted to the publication of Matsuda's "Plant Catalogue in Ningbo, Zhejiang Province"(a modern scholar calls for: just like commemorating Zhong Guanguang, the pioneer of the modern phytology, there should also be a botanical name that can commemorate Zhang Zhiming of making up for the shortcomings of the scientific history of Whiggish.) [2]. During this period, Zhang Zhiming often travel between Japan and Shanghai. He fully understood the differences and disadvantages between the "private school" and the "foreign school". He always asked his clansman to set up schools when he returned home. In the winter of 1905, the clansman decided to adopt his proposal, invested in repairing the school house and bought equipment immediately. In the spring of 1906, this new school named Zhang's Private Three-Pool School opened.(In 1930s, Shi Lutou's family edited the genealogy and attached the "Three-Pool School Record" to commend Zhang Zhiming's achievements in education [3]. At the beginning of 1911, Zhang Zhiming opened a new Scientific Instrument House managed physical and chemical equipments, teaching sample models and so on in Shanghai's Qipan Street (the two sides of Henan Road between Yan'an East Road and Fuzhou Road, now there are no commercial markets and the geographical names have disappeared). After the business of this museum became stable, Zhang Zhiming went to Japan to purchase the equipment by himself. At the end of 1924, he began to live in Shanghai to run his own Scientific Instrument House. In December 1929, Zhang Zhiming was recruited by the first curator of the West Lake Museum in Zhejiang Province as the director of the History and Culture Department of the Museum. He had successively visited Yuhang and Pingyao in Hangzhou, Huai'an in Zhangjiakou, and Luoyang in Henan Province to acquire antiquities for museum. In September 1932, the Jixian Documentary Committee was established and Zhang Zhiming became a member of the committee. In mid-August 1933, due to the controversy of the Central Library's preparatory office copied the "Rare Books" in the "Si Ku Quan Shu", he jointly signed with 25 book collectors or academics such as Dong Kang, Fu Zengxiang, Chen Yuan, and Chen Yinke to the Ministry of Education. They suggested "He who can replace him should use his copy, and the name, scope, and content of the copy should be considered [4]." During the Anti-Japanese War, he served as a director of the Shanghai Zhang's Sinology class and a special member of the China Quanbi Institute. In his later years, Zhang Zhiming handed over the business of the Scientific Instrument House to his cousin Zhang Chunnian, who was 12 years younger than him. Then he dedicated his time to read and write in the Gu Huan Room and studied the table spectrum. In about 1947, Zhang Zhiming died in Shanghai. In 1954, his books were sold by his descendants.

Zhang Zhiming loved books, collected books and also preferred to make friends with literati. He had great social relations with Zhang Taiyan, Tao Chengzhang, Ren Jin, Chen Hanzhang, Ma Xulun, Yu Heqin, Yu Yunxiu, Wang Xiantang, Ye Gongchuo and so on. Including some Modern scholars such as Zhang Shouyong, Gu Xieguang, Hu Pu'an, Ma Heng etc. Some of Zhang Zhiming's friends have written inscriptions, pictures, paintings for his room. For example, in 1891, Mr. Liu Pei-en of Zhenhai inscribed "Heng Lu" and written a prose for his room. In 1933, Zhang Daqian, a master of modern Chinese painting, painted a picture called " $\mathrm{Gu}$ Huan Room for the Collection of Ancient Books". In 1936, Ren Jin, a modern calligrapher, wrote an inscription and an autograph for Gu Huan Room. The great master of modern calligraphy Sha Menghai engraved the seal of "Zhang Zhiming", "Zhang Zhiming Yin" and "Zhang Zhiming Zi Bo'an". Some of his friends wrote articles and poems to praise his book collection practice. For example, Zhang Taiyan wrote Gu Huan Room in 1931. [5] (This article was published in 1935 in the Shi Lutou Genealogy (Vol. 4), Miscellaneous Record and reprinted on Yinxian Chronicles and Literature, which was published in 1951.), detailing the origin of the practice of book collection and its historical function. Ma Xulun said in the Shi Wu Yu Shen published in 1948: "Zhang Zhiming, first made his fortune by doing business, found the Scientific Instrument House in Shanghai. He was fond of collecting books, those books were first hidden in Japan but were destroyed by a massive earthquake. Now he still have tens of thousands of book collections in Shanghai [6]." Zhang Zhiming's friend Yu Heqin, who tried the practice of sinification of science with him together, also wrote Gu Huan Room, as he writes: "My friend Zhang Bo'an is addicted to books. He did business in my hometown Chai Qiao when he was young, he earned money every month and used it to buy books; when he grows up, he earns a lot of money every month and he buys more books; As business grows better and better, he begins to do business in Japan and gets a lot of money and he buys more books. Whether he has money or not, what he wants to do first is buying precious books. Having returned from Japan, Zhang Zhiming opened a bookstore in Shanghai and named it as "Gu Huan Room". With apparatus fit downstairs and books placed upstairs, he read during the daytime. Cramped as the space in it could be, the books are everywhere, including ones on the bed. What's more, the guests come to talking about books heatedly or going out together to purchase some books at all costs are the deeds they prefer. Therefore, scarcely does he encounter his wife and his son who rest next door [7]." At the end of Yu's article, a poem with a length of four words was attached to the book to praise Zhang Zhiming's interest in finding and collecting books and his character of dealing with people. (this poem was named as Gu Huan Room Chant, published in 1935 in the Shi Lutou Genealogy (Vol. 4) later • Miscellaneous Record.) At the time of Zhang Zhiming's 70th birthday, more than 30 of his peers, 
such as Gao Zhenxiao, Jiang Weiqiao, Yu Heqin, Hu Pu'an, $\mathrm{Gu}$ Xieguang, Ma Heng, and Wang Wanwen created poems to honor his birthday which made it a much told tale in intellectual circles [8].

\section{The Pleasure of Collecting Books}

Zhang Zhiming had a habitual addiction to books. He started buying and collecting books at Chai Qiao, Zhenhai country in the early years and named his room also a library as "Henglu" and "Hengzhai". At the beginning of the 20th century, when Zhang Zhiming lived in Tokyo, he discovered many old books sold from China and lamented that "in less than a century, Chinese books will disappear" and "collecting scattered books to return to China" [5]. He got more than 10,000 volumes of Chinese and foreign books and built three libraries which were named as "Gu Huan Room" in the Kyohashi district of Tokyo to place these books . In the fall of 1923, the books were destroyed by earthquake in Tokyo. In response, Zhang Zhiming once wrote: "The books, paintings, furniture and other things purchased in the library each year are all burned to ashes, and the personal losses are also in the 30000 to 40,000 yuan. The most unfortunate thing is that the solitary books, rare books, and good books that I acquired over the years have become scorched. What a pity [9]." After returning to Shanghai in late 1924, he continued to collect a large number of books and used the living room upstairs of the Scientific Instrument House as a library, still in the name of "Gu Huan Room".

Zhang Zhiming's search for books and collection of books can be described as obtaining whatever he aspires for at any costs. If he is informed that there is a rare edition, he must make an acquisition. Even if the funds are lacking, he will not hesitate to borrow money to acquire. In 1935, he edited "the Catalogue of Zhang's Gu Huan Room Collection"(after Zhang Zhiming's death, this catalogue was collected by his friends also a collector, Feng Menggao, and now it is collected in the Ningbo Tianyi Pavilion). Although the bibliography is not clearly categorized, the books are generally arranged in four parts: Confucian classics, history, philosophy and literature. There are books such as the rare books, precious editions, original publications, hand-copied books, manuscripts, lithographs, and box books of which their version informations and the number of chapters and volumes are clear. But for his books, Zhang Zhiming can check them out without looking at the catalogue, even at the age of 70 . The extent to which Zhang Zhiming is familiar with his books is evident.

Zhang Zhiming's collection of books also covers activities such as copying, collation, inscription, publication, and printing. For instance, he has ever transcribed " Read and Take an Examination of the Original"; Treasuring up the revised version by Gu Yu in Yushan in Qing Dynasty of "Pi-Ya" (with 20 Volumes) composed by Lu Dian in Song Dynasty, he has complementally added the missing volume 11 to the work with ample annotations and revisions; Also, he has completed a copy of a third Jiaqing block-printed version of "Identifying and Eliminating Confusions from Varieties of Books" after a proofreading based on the inscription by Zhou Shixu; Subjoining his own postscripts to the block-printed version of "The Beginnings of All Dynasties" coming out in the twenty-seventh year of Qianlong (1762) from the "Ruiliutang" that compiled by Liu Sishu was one of what he accomplished as well; By feat of the culture site known as "Tongyiguan" set up by himself, he has published "Annotations of "The Prajnaparamita Heart Sutra"” (the thread-stitched one, printed in 1921). Zhang Zhiming's collection of books is all stamped with his collected seals. Added up personally, his collections of seals consist of " The Collection of Four from Ming Dynasty of Zhang's 'Gu Huan Room"”, "The Collection of Zhang's 'Gu Huan Room' in Ancient Yin", "The Collection of Gu Huan Room"”, “The Seal of Zhang Zhiming's 'Gu Huan Room"”, "The Hoard of 'Gu Huan Room", "The Collection of 'Heng Cottage' in the Southern Yin", "The Collection of 'Heng Cottage"”, "Zhang Zhiming's Treasure", "Zhiming's Treasure", "Zhang Zhiming" (with the characters concavely carved on it), "Zhang Zhiming" (with the characters embossed on it), "Notes of the Collection of Four from Ming Dynasty in Zhang's 'Gu Huan Room"”, "The Notes of the Collection of Zhang Zhiming", "Gu Huan", "The Collection of "Gu Huan Room", "The Seal of Zhang Zhiming" (with the characters concavely carved on it), "The Seal of Zhang Zhiming" (with the characters embossed on it), "Zhang Zhimingm, Boan", "Zhang Zhiming Cherishing the Old" (some of his seals are now collected in the museum known as Ningbo Tianyi Pavilion. And according to Mr. Fan Fengshu's statistics [10], among the book collectors in China, Zhang Zhiming should be the one who have more number of collection seals.

The naming of the study and the selection of the characters on the seals apparently embody the owner's preference, aspiration and taste in the private collecting of books. As named "Gu Huan Room", the study clearly reflects Zhang's spirit of a ceaseless pursuer with tremendous efforts for the ancient books which are cherished by him as lifelong intimates; As called "Heng Cottage", "Heng Hut" respectively, the two buildings represent his sheer perseverance of searching for and storing up the books. The seal with "Zhang Zhiming Cherishing the Old" signifies his embosoming the cherished and his belief in their usefulness in the near or far future. To fully demonstrate Zhang's affection and persistence, his friend Ma Heng has composed a poem:

Missing are Myriads in the well-known hall of learning; Questing are you all alone for the treasures in trudging; All year round strenuously searching and solely insisting,

You leave the bibliotheca for the compilation approaching [11].

Quite similar to the mentioned above, what Yu Heqin, another one of Zhang's friends has indicated also builds an image of Zhang as an absolute bibliophile: never will he be altered by hardships in the mundane world but always he is the one who treats his friends with massive courtesy and spends enormous sum of money to attain what he hankers after. Who could be the one completely understand the glee from 
collecting the outmoded apart from him? [7]

\section{The Characteristics of Zhang's Collection}

So wide is the range of his collected books that it can embrace the ones from the previous times or in the contemporary and the ones with great extensiveness and detailedness, ranging from the Collection of Si Bu, Buddhist sutras, Tao books to tablets of calligraphy and paintings, maps. In accordance with "The Catalogue of Zhang's collections of 'Gu Huan Room' in the Southern Zhejiang” compiled by him in 1935, there were one thousand sorts of and eight thousand one hundred volumes of his collected ones. Of them is the majority of books of thread-bound version, and besides are reliable and rare ones, the only existing copies, and some Japanese block-printed ones: the reliable ones represented by "The History Records of Mughal" by Tu Ji (with 160 volumes, 50 books), "Essentials of Historical Geography" by Gu Zuyu (with 9 volumes, 10 books), "Xu's Textual Research on Geography" by Xu Hongpan, "Records of Baiyun Cave" by Huang Heng; Rare ones including "Yi Yin" by Cao Xijiu (hand-copied with 8 volumes, prefaced by Xie Sanbin), "Experience of Reading 'Yi'" by Han Yi (with 12 volumes), "Records of Matters in Ming" by Quan Zuwang (hand-copied one with 20 volumes from the Baojinglou Press), "The Whole Records of Zheng Family in Taiwan" by Shen Yun (with 6 volumes) [12]; ( For more details of rare ones, do consult "Documents of Literature about Yin"). The only existing copies of some composed of "A Brief Compilation of Zhou Ji" (the manuscript with 4 volumes) and so forth; The Japanese block-printed ones comprising "Grasping the Six Categories of Chinese Characters" compiled by Min Qiji (with 4 volumes), "Essentials of Huangshan Mountains" by Wang Hongqing, "Academic Journal of Suzhou University" by Wang Fu and so on. Moreover, various kinds of versions of the same books are held in his treasury, such as two versions of "Dynastic Histories from the Antiquity to Ming Dynasties", three versions of "The Golden Lotus" and "River Systems".

What does stick out his collection is the majority on numismatics as many as 37 in volumes and 125 in books: reliable ones of "Annotations of Yuxiashujin" ( printed by Guangu Hall of Bao Zinian), "Compendium of Ancient Wells" (the fourth version from Song and Liao Dynasties); rare ones of "Quatrains of the Theory of the Wells" by Liu Yanting, "Yarns of Foibles" and "The Records of Yong Well in the Period of Zhaohe" both by Cai Yun. Apart from these, some western versions sink flow to Zhang's treasury as well, covering "The Records of the Copper Cash in China" and "The Records of Exchanging Currencies in the Early Phase in China". Because of his immense efforts in this domain, the colossal credit has gone to him with the special membership of Chinese Currency Society previously set up in 1940 [13], alongside with the entry of "Figure" in "The Dictionary of the Chinese Coin" emerging in 2007 published by Zhonghua Book Company [14].
The science and technology books winning a marginal place in Zhang's collection, it can be represented by "Query into Herbs" (the Japanese version), "The Records of the Critical Thinking of Herbs" (privately printed by Zhou in the 30th year of Gangxu), "River Systems" by Li Daoyuan ( the letterpress version) and the like. However, in Zhang Zhiming's collection of science and technology books, books of biology, medicine, pharmacy and geography comprise the majority.

\section{The Utilization of the Collected Books}

Absorbing tremendous nutrients from what has been accumulated, the fruits of Zhang's research are born from the stems of the modernization of portraying and editing maps and the study of table spectrum. Utilizing the collected books ("The Records of the Oversea Experiences" by Chen Jionglun, "The Strategically Important Sites of Waterways in China" translated by Chen Shoupeng), he has ever drawn and modified a certain number of modernized maps. What's more, the composing and revamping of "The Full View of Ningbo" (published in 1910, collected presently both in Ningbo Tianyi Pavilion and Zhejiang Library), "Islands Near Zhejiang and Jiangsu" (published in 1910 rarely collected presently with one ever auctioned off in the spring of 2005 in the art auction of Shanghai season in the part of the ancient books), "The New Preface Chinese Provinces'Maps [15]" (finished in 1914 with one made by $\mathrm{Gu}$ Xieguang but without any surviving copies presently are all what he has accomplished.)

Also occupying an important position, the historical and annual ones are comprised of "The Textual Research of the Circle of Sixty Years of Past Successive Years" (with one volume) by Huang Zongxi, "The Brief Record of Ryukyu Kingdom"(with sixteen volumes) by Zhou Huang, "The Annual Record of Korea" by Japanese composer Senrun Sanlang and so on. Utilizing all these great works, he used to compile a series of his representatives which are tremendously typified by "Annuals of Zhang's 'Gu Huan Room'” containing six kinds and from the first to the sixth one, they respectively are: "The Integrated Records from the Western and Eastern of the beginning years of Emperors' Reigns" (with two volumes), "The Tabulations of the Past Emperors" (with one volume), "The Annual Records of the Circles of the Past Dynasties" (with two frames), "The Brief Sketch of the History Read" (with one volume) and so forth. With all these are "The Brief Tabulation of the Beginning Years of the Reigns of the Past Emperors" (finished in 1928 with one volume), "The Integrated Research of Jianyuan of the Past Dynasties" (finished in 1928 appended by"The Brief Research and Supplement of the Reigns' Titles of the Past Dynasties" with one volume), "The Brief Research of the Tabulations of the Past Dynasties", "The Newly Compiled Annual Records of Korean and Japanese Tabulations (the Integrated One)", "The Newly Compiled Annual Records of Annan", "The Newly Compiled Annual Records of Ryukyu", "The Scripts of the Life Chronicle of the Owner of 'Gu Huan Room"' (composed in 1938), "The Diverse Researches of the Date of the Birth and Death of Buddha Shakyamuni" (containing the combined 
issue of the periodicals of the 125th to the 126th one "The Buddha's Compassion While Serving the People") and so on. And of all the above mentioned ones, except "The Integrated Records from the Western and Eastern of the beginning years of Emperors' Reigns" (with two volumes) and "The Annual Records of the Circles of the Past Dynasties" (with two frames) are printed out, all the rest are manuscripts. ${ }^{(1)}$

Not only have the collected ones brought relish to Zhang himself, but also they have been taken to share benefits with his contemporaries. Desperate for "Query for Herbs" and having failed to obtain it in the bookstores in Japan, Zhao Juhuang, the widely acknowledged Chinese pioneer in pharmacy eventually attained one in "Gu Huan Room [16]". Similar to Zhao, when immersed in editing "Series of Four Ming", Zhang Shouyong has taken advantages of the rare ones borrowed from "Gu Huan Room", including "Collections from Qian Zhongjie" redacted by Quan Zuwang (the hand-copied one), "Collected Works from Liubu Hall" (the hand-copied one from the Baojinglou Press), "The Extra Collections of Futai"( an ancient hand-copied one with 2 volumes). And dedicating some of his books to libraries for convenience for more people, Zhang has, representatively, contributed 64 volumes classified into 7 sorts of books with illustrations covering "The Historical Records" and "The Records of Imperials" to the Luo's library of Shanghai St John University [17].

\section{The Dissemination of the Books}

Hardly could the collection of books be reserved for a wide span of period as long as one hundred years. Zhang's collection in Gu Huan Room is no exception. Similar to the books in Japan being unfortunately committed to the flames caused by the earthquake, the collected ones in Shanghai was constantly sold out by his family in 1954 , being recollected by the sellers and the collectors of the ancient books. And it has been said that Xuan Xijiang, the past assistant manager of the Shanghai Ancient Books Store is the one who gained the most [18]. Having been passed down for a quite large span of time, some of Zhang's collected books are nowadays gleaned by a profusion of public libraries and university libraries. And all these public libraries feature the Shanghai Library and the Ningbo Tianyi Pavilion. Through the search of CALIS "College of Ancient Documentary Resources", there are nearly 50 records of Zhang Zhiming's collection of books with his seals. They are displayed in university libraries such as Peking University, Renmin University of China, Xiamen University and Liaoning University. Some also flowed to the

(1) In the various manuscripts of Zhang Zhiming's collection, the "The Integrated Records from the Western and Eastern of the beginning years of Emperors" has not been published, but it was Zhang Zhiming's most dedicated work. In the 1950s, this manuscript was once in the market, and the modern collector and version appraiser Pan Jingzheng saw it and cost a lot of money to buy it. He then wrote a record about it. "The Newly Compiled Annual Records of Annan","The Newly Compiled Annual Records of Korean and Japanese Tabulations (the Integrated One)" and "The Scripts of the Life Chronicle of the Owner of "Gu Huan Room" are now in the Shanghai Library, other manuscripts are missing. university library in Hong Kong and Macau. For example, in library of The Chinese University of Hong Kong, it has book "The Biography of Ziyan Lay Buddhist" revised by Cheng De, compiled by Zhang Jun and printed by Tongzhi Hall in Beijing (stamped by the seal of " The Book Seal of Zhang Zhiming in Ancient Yin"). University of Macau's library has collected "Xia Tang Poetry Anthology" revised by Wang Zongxian and printed in Qing dynasty.(stamped by the seal of "Zhang Zhiming's Treasure”, “Gu Huan Room” ). Through so many marks in books, we can clearly see that the collection of Zhang's Gu Huan Room has complemented the functions of modern Chinese library books, especially ancient books.

There is a part of Zhang's collection of books, which is still circulated in the society, sold in antique market and traded on the Internet or at auction. "Meritorious Statesmen in Ling Yan Hall" by Tao Xiang She Yuan Press, "The Brief Record of Xiao Hui" printed by Zhong Hua Press, "Three Great Greek Philosophers" translated by Chen Peng and printed by Guang Zhi Press and so on are all included in his enormous collections.

Although Zhang's collection of books were scattered afterwards, they were still in China. Compared with some of his contemporary book collectors, Zhang Zhiming's practice of collecting books may not be worth mentioning. But hundreds of years later, when people see his collection of books, they may share the same feelings with Zhang Taiyan and Ye Gongchuo that Zhang Zhiming can be compared with his counterparts like Wanjuanlou's Feng, Tianyige's Fan and the Qin and Han dynasties' book collector Fu Sheng.

\section{Conclusion}

According to Mr. Fan Fengshu's statistics, there are only $1.7 \%$ of industrial businessmen among the book collectors in China. Zhang Zhiming was a merchant, but he was a so-called one of thousands of people [19]. His collections involve ancient and modern ones within or outside China, among which there are some science and technology books that are not collected by ordinary book collectors. This may be related to his experience in sinification of science. His action of searching and collecting books and other related activities are based not only on a batch of Chinese cultural relics flowing to other countries such as Japan during the Late Qing Dynasty and Early Republic of China, but also because of the Chinese traditional culture and the hometown's culture of collecting books. It is also related to his nature of loving books and the knowledge he has learned in Japan and Shanghai. His practice of collecting books has contributed to the inheritance and protection of Chinese culture to a certain degree, leaving an indelible impression in the history of modern Chinese culture.

\section{References}

[1] Ye Gongzhuo. "Writing for "The Collection Drawing of Zhang Bo'an (Zhiming)'s Gu Huan Room"”. In: Xia'an Huigao. Shanghai: Shanghai Bookstore Publishing House, 1990:165. 
[2] Liu Su. The story of the plant name. Beijing: The People's Posts and Telecommunications Press, 2013:74.

[3] Zhang Zhaoyuan. "Three-Pool School Record”.In: Shi Lutou Genealogy (Vol. 4). Famous Church's Wooden type, 1935:39.

[4] Dong Kang etc. "Comments on the preparation of the $\mathrm{Si} \mathrm{Ku}$ Quan Shu”. In: Shun Pao, 1938-08-13(18).

[5] Zhang Taiyan. Complete Works of Zhang Taiyan (5). Shanghai: Shanghai People's Publishing House, 1985: 347-348.

[6] Ma Xulun. Shi Wu Yu Shen. Shanghai: Jianwen Book House, 1948:70-71.

[7] Yu Heqin. "Gu Huan Room”. In:Primitiae Heqinwen (V.2). 1938:14-15.

[8] Qing Yu. "The Story of Zhang Bo'an". In:Ningbo People Weekly, 1946(3):15.

[9] Zhang Zhiming. "The 12th year of the Republic of China (1923, 52 years old)". In:Gu Huan Room owner write the annual draft (manuscript). Shanghai Library Collection.

[10] Fan Fengshu. History of Private Collections in China. Zhengzhou: Elephant Press, 2001
[11] Ma Heng. Ma Heng Diary (with poems): The Forbidden City around 1948. Beijing: Forbidden City Press, 2006:259.

[12] Zhang Chuanbao etc. Yinxian Chronicles (Volume 4). Ningbo: Yinxian Chronicles Museum, 1951: 2061-2064.

[13] "Member of the China Quanbi Institute". In: Quanbi, 1941(4):48-49.

[14] Edited by the Editorial Board of The Dictionary of the Chinese Coin. The Dictionary of the Chinese Coin: Quanren's Works. Beijing: Zhonghua Book Company, 2007:84.

[15] Gu Xieguang. “The New Preface Chinese Provinces'Maps". In: Literature \& Art Magazine, 1914(10):16-17.

[16] Zhang Shuxue, Zhang Baoyi. Zhao's Chinese Famous Talents. Jinan: Taishan Publishing House, 2005:261-262.

[17] Huang Weilian. Luo's library of Shanghai St John University. Shanghai: Luo's library of Shanghai St John University, 1932:28.

[18] Huang Shangzhu. Reading in Lai Yan Xie(Lower volume) [M]. Shenyang: Liaoning Education Press, 2001:78.

[19] Wang Wanwen. “The Introduce of Mr. Zhang Bo'an's Writings". In:Ningbo People Weekly, 1946(3):15. 